\title{
Correction to: Leveraging HPC accelerator architectures with modern techniques - hydrologic modeling on GPUs with ParFlow
}

\author{
Jaro Hokkanen $^{1}$ (D) $\cdot$ Stefan Kollet ${ }^{1} \cdot$ Jiri Kraus $^{2} \cdot$ Andreas Herten $^{3} \cdot$ Markus Hrywniak $^{2} \cdot$ Dirk Pleiter $^{3}$
}

Published online: 12 August 2021

(C) Springer Nature Switzerland AG 2021

\section{Correction to: Computational Geosciences} https://doi.org/10.1007/s10596-021-10051-4

The original publication of the article contains major typesetting and production errors introduced by the publisher. During proofreading, corrections provided by authors were not honored by the publisher.

The original article has been corrected.

We sincerely apologize for any inconveniences caused.

Publisher's note Springer Nature remains neutral with regard to jurisdictional claims in published maps and institutional affiliations.

The online version of the original article can be found at https://doi.org/ 10.1007/s10596-021-10051-4

Jaro Hokkanen

j.hokkanen@fz-juelich.de

1 Agrosphere (IBG-3), Forschungszentrum Jülich GmbH, Jülich, Germany

2 NVIDIA GmbH, Würselen, Germany

3 Jülich Supercomputing Centre (JSC), Forschungszentrum Jülich $\mathrm{GmbH}$, Jülich, Germany 